\section{CONSUMO E SUAS SENSORIALIDADES: DO VISUAL, DO VERBAL E DO OLFATIVO}

O volume 10, número 2, da Signos do Consumo integra oito artigos científicos, uma resenha e, pela primeira vez, entrevista com um pesquisador destacado da área de comunicação e consumo. As reflexões teóricas e os temas tratados concentram-se nos sentidos da visualidade, das manifestações verbais e, ainda, dos signos olfativos, todos como caminhos consequentes na busca de potencializar as relações e os rituais de consumo, mediados pelas marcas.

Assim, o primeiro artigo desta edição é de Guilherme Nery Atem e Fernanda Ferreira de Abreu, da Universidade Federal Fluminense (UFF) do Rio de Janeiro. O texto apresenta a análise das relações entre consumo de experiências e o sentido humano do olfato. O objetivo dos autores foi mapear as produções acadêmicas que contemplaram essa relação, tendo como base diferentes abordagens científicas. Constataram, com isso, que apenas recentemente as ciências humanas e sociais e a publicidade, em particular, vêm se interessando pelos sentidos produzidos pelo olfato nas interações de consumo. Daí a relevância dessa reflexão de caráter exploratório, a partir das principais formulações teóricas relativas ao assunto, adicionando empiria focada em pontos de venda com exploração olfativa. Tema inovador e relevante no contexto da expansão das sensorialidades marcárias contemporâneas.

"Emojis na Publicidade e seus significados para marcas e consumidores: tipologias e questionamentos” é o artigo de Bruno Pompeu e Silvio Sato, ambos da Escola de Comunicações e Artes da Universidade de São Paulo (ECA/USP). O texto apresenta uma reflexão sobre o uso dos emojis, com ênfase na apropriação desses códigos visuais pela comunicação das marcas. Os autores constataram que os emojis são utilizados na publicidade de distintas formas, com significados negociados de maneira múltipla e com a crescente participação e colaboração do público, caracterizando um caminho dialógico. Nesse sentido os autores propõem, a partir da semiótica peirceana, uma tipologia para o entendimento desse fenômeno midiático recente por meio de uma proposta de classificação de usos de emojis na publicidade. Trata-se de abordagem inaugural e sistematizadora dessa importante linguagem midiática.

Sandro Tôrres de Azevedo (Faculdades Integradas Hélio Alonso), Daniele de Castro Alves (Universidade Estadual do Rio de Janeiro) e Mariana Ayres Tavares de Vasconcelos (Centre d'Études Luttéraires et Scientifiques Appliquées Paris-Sorbonne) apresentam o texto "Novos enunciadores da publicidade: perfis fictícios no branded content da cerveja Antarctica”. Nesse artigo os autores expõem as análises das interações estabelecidas na página do perfil fictício Marcelão da BOA, personagem da websérie "Coisa boa gera coisa boa”, promovida pela marca de cerveja Antárctica como parte integrante de sua estratégia de conteúdo de marca. Para tanto, recuperam os conceitos afeitos à relação entre ciberpublicidade e prossumidores (consumidores produtores), bem como revisitam algumas perspectivas teóricas sobre branded content. Por meio do corpo teórico da sociossemiótica, os autores investigam as trocas discursivas entre marca e consumidores sob o prisma dos regimes de postulados nessa teoria.

Rodrigo Stéfani Correa, professor da Universidade Federal de Santa Maria (UFSM), apresenta o artigo "Publicidade, institucionalidade e

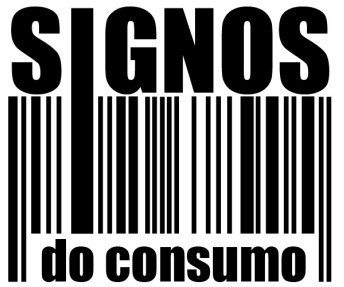

apresentação 
formação publicitária”. As reflexões por ele apontadas compreendem a primeira fase da pesquisa interinstitucional com a temática do ensino de criação publicitária e repercutem os trabalhos exercidos na Escola Superior de Propaganda e Marketing de Porto Alegre (ESPM-POA), na Universidade Federal de Pernambuco (UFPE) e na UFSM. O objetivo principal nessa etapa apresentada no texto foi explorar as práticas de ensino consideradas institucionalizadas, fundamentais para 0 entendimento de determinadas características pedagógicas favoráveis aos sentidos de "inovação" nas dinâmicas do ensino, principalmente nas disciplinas de criatividade. As teorias de base são as proposições teóricas de Piaget, Edgar Morin e Vygotsky, no que se referem aos processos de orientação, onde se coloca em perspectiva três dimensões específicas, mas articuladas: interação, técnicas e condições de ambiência. Essas dimensões são ainda tencionadas pelas projeções de Berger e Luckmann e outros colaboradores. Trata-se de pesquisa inovadora e muito oportuna, uma vez que estamos este ano em meio às discussões das novas diretrizes curriculares para os cursos de publicidade no país.

Os pesquisadores da Universidade Federal Rural de Pernambuco (UFRPE) Isaac Matheus Santos Batista, Marcelo Machado Martins e Raquel de Aragão Uchôa Fernandes apresentam o texto "Procedimentos essenciais do processo de colonização das práticas cotidianas de consumo pelo lugar de poder da produção”. O artigo tem o objetivo de compreender os procedimentos inerentes ao processo de colonização das práticas de consumo cotidianas a partir do lugar de poder que a produção instaura. Por meio de um estudo de caso da maison de alta costura Dior, que ocupava/ocupa lugar de poder dentro do sistema de moda, o texto demonstra os caminhos de como a marca colonizou as práticas de consumo de vestuário dos jovens e da classe trabalhadora dos anos 1960 na França e na Europa, inspirando-se nos trajes surgidos entre eles para concepção de novos produtos de luxo. Assim, os autores percebem que existem quatro procedimentos inerentes ao referido processo: reconfiguração, refuncionalização, ressignificação e eticalização. É um texto muito interessante e reflexivo sobre as relações entre marca, poder e consumo de moda.

Eliã Siméia Amorim e Elis Rejane Santana da Silva, da Universidade Estadual da Bahia (Uneb), e Jessica Rosa, da Universidade de São Paulo (USP), apresentam "O princípio do prazer: o hiperconsumo como escape em tempos de modernidade líquida". O artigo debate o panorama contemporâneo, demarcado pela metáfora da modernidade líquida introduzida por Zygmunt Bauman, que a caracteriza como fase atual em que as tradições enraizadas ao longo dos séculos vão se diluindo e revelando um alvorecer ambíguo, tanto do ponto de vista tecnológico quanto do ponto de vista das relações inter e intrapessoais e de consumo. Estabelece ainda relações com reflexão do mesmo autor contida em Vida para o consumo, fazendo análises que vão encontrar sustentação nas argumentações da teoria do Hiperconsumo de Gilles Lipovetsky, transcrevendo uma trajetória que elucida pontos nevrálgicos da sociedade do consumo, bem como do Homus consumens, que emerge desse alvorecer nas paisagens líquidas. Para adensar a reflexão, o estudo utilizou-se da análise das obras contemporâneas japonesas da arte Muji, que busca romper com o princípio do consumo líquido, acelerado e individualista, próprio dos tempos dessa modernidade tardia, ainda que o êxito seja tão somente parcial. 
"Pintura de paisagens amazônicas: o design vernacular em Mosqueiro (PA)" é o artigo das autoras Natália Cristina Rodrigues Pereira e Célia Regina Trindade Chagas Amorim, da Universidade Federal do Pará (UFPa). O texto discute a experiência comunicacional e estética na Amazônia, que na academia recebe o nome de design vernacular. Refere-se aos desenhos de letras, ilustrações e paisagens pintados à mão que, baseados na cultura popular, objetivam suprir as necessidades comunicacionais do comércio informal onde se originam, sendo importantes para as comunidades locais, pois são manifestações de sua cotidianidade. A ênfase da análise está na discussão da pintura de paisagens a partir da pergunta: de que forma o design vernacular, na sua modalidade paisagística, expressa a cultura amazônica? Trata-se de destacado texto que materializa a riqueza da diversidade e da mestiçagem brasileiras expressas na cultura visual popular.

O último artigo é de Frederico Jorge Tavares de Oliveira, da ESPMSP, intitulado "Por uma teoria da consumação: correspondências entre comunicação, consumo e imaginário”. No texto pretende-se indicar a consumação como categoria teórica pertinente para se estabelecer rotas teórico-metodológicas para os estudos de comunicação e consumo na sua relação com o conceito de imaginário. Os caminhos adotados levaram à revisão bibliográfica de autores que integram esses estudos, incluindo pesquisas multidisciplinares sobre o imaginário. A partir daí o autor apresenta vários conceitos articulados entre si a fim de que se possa compreender a formação das imagens simbólicas num ambiente de consumação mediática. A hipótese do autor está centrada na insuficiência das categorias do consumo e do consumismo para lidar com essa questão. Ainda que seja muito inicial essa constatação, sugerida ao final do texto, o artigo é importante pelas reflexões que sugere.

Pela primeira vez a revista Signos do Consumo incorpora em sua edição uma entrevista, prática que deveremos seguir nos próximos números, uma vez que configura um meio de troca, reflexão e avanço do conhecimento que se apresenta na vivacidade do diálogo. Quem debuta nesse formato é Oscar Cesarotto, psicanalista e professor do Programa de Comunicação e Semiótica da Pontifícia Universidade Católica de São Paulo (PUC-SP), apresentando a relação entre semiótica e psicanálise experimentada e teorizada por ele no Brasil, há mais de trinta anos, tanto no ensino quanto na extensão e na formação de mestres e doutores, como também em suas publicações. O título da entrevista, "Semiótica psicanalítica para crianças de 0-99 anos-luz”, transmite seu tom inventivo e ao mesmo tempo muito didático, próprio da maturidade na pesquisa. Excelente leitura.

A resenha que encerra esta edição, "Produção e consumo digital e o museu de favela: ampliando as vozes da periferia", é de autoria de Arize Souza Fernandes de Oliveira, mestranda da Universidade Federal do Rio de Janeiro (UFRJ), e foi baseada no livro Antropologia digital e experiências virtuais do Museu de Favela, representando uma ótima síntese construída pela autora.

Desejamos a todos ótima leitura. 